Бабак В. П., Щепетов В. В., Супрун Т. Т., Бильчук Е. Ю.

Институт технической теплофизики НАНУ. Украина, г. Киев

\title{
ИЗНОСОСТОЙКОСТЬ ПОКРЫТИЙ ПРИ АННИГИЛЯЦИИ ЭНДОГЕННЫХ ЭКСТРЕМАЛЬНЫХ ДЕФЕКТОВ В УСЛОВИЯХ ТРЕНИЯ
}

\begin{abstract}
Предложен механизм блокировки и последующей аннигилящии эндогенных микротрещин за счёт их внутриструктурной самокоррекции.

Установлено, что при трибомеханических процессах фрикционного взаимодействия в условиях аддитивного влияния температурных флуктуаций и удельных нагрузок в контактной зоне имеет место одновременное действие всех возможных с точки зрения физико-химии аномальных превращений в твёрдой фазе. Результатом которых является термическое разложение карбидов и образование структурно свободного $\alpha$-графита.

Результаты, полученные при испытаниях, позволяют предположить, ито антифрикционный поверхностный слой, содержащий графит, образуется в режсие приработки и его состав, как и равновесная шероховатость, воспроизводятся и поддерживаются, образуя целостную систему динамически устойчивых износостойких структур, во всём диапазоне нормального износа. [dx.doi.org/10.29010/080.2]
\end{abstract}

Ключевые слова: детоначионное покрытие; износостойкость; поверхностный слой; структурная приспосабливаемость; легирование.

\section{Введение}

Среди проблемных технологических вопросов, связанных с поверхностной прочностью металлических материалов при трении, процессы повреждаемости, как обратная сторона регенерации, занимает особое место. Виды повреждаемости многообразны, а последствия, зачастую, одинаковы. Процесс может быть представлен как результат образования и последующего роста экстремальных дефектов, представляющих собой микрообласти с частично или полностью нарушенными межатомными связями (берега трещин), инициируемых пластической деформацией. Изучение процессов зарождения и развития разрушения, так же как и торможение и регенерация трещин в материалах, является актуальной задачей.

Известны работы [1,2], в которых представлены результаты изучения закономерностей влияния всестороннего давления и температуры на кинетику процесса залечивания пор и трещин по границам зерен в поликристаллических материалах.

Получены данные [3, 4] исследования трансформации дефектов типа плоских микротрещин в материале тел под воздействием высокоэнергетического импульсного электромагнитного поля, в которых рассматриваются процессы, протекающие в материале при обработке металлических образцов кратковременными импульсами электрического тока большой плотности.
В работах $[5,6]$ изложены результаты экспериментальных испытаний влияния обработки импульсным магнитным полем образцов с трещиной на их сопротивление разрушению. Отмечено, что обработка приводит к релаксации напряжений вследствие пластического течения в вершине трещины, что приводит, как правило, к ее притуплению.

В работе [7] проанализированы исследования структуры и свойств металлов, деформирование которых происходит при высоких постоянно действующих гидростатических давлениях. При этом, как установлено, чем больше сжимающие напряжения, тем больше пластическую деформацию может претерпеть материал без разрушения.

Оценивая в целом состояние исследований, как в нашей стране, так и за рубежом, можно отметить, что существующие технологии малоэффективны и их реализация представляет определенные сложности в условиях эксплуатации, особенно в нестационарных режимах и не имеет простого и надежного решения для реального производства.

В поверхностных слоях при нагружении трением образуются микротрещины и поры, кинетическое развитие которых определяет ресурс долговечности подвижных сопряжений. Однако, в свою очередь, создание условий их торможения и регенерации может быть одним из перспективных путей повышения износостойкости и долговечности деталей. 
Целью работы является исследование пути повышения износостойкости детонационных покрытий за счет внутриструктурной аннигиляции эндогенных экстремальных дефектов при нагружении трением.

\section{Методика исследований}

Детонационное напыление наноразмерных композиционных покрытий осуществляли нанопорошками системы $\mathrm{Nb}-\mathrm{V}-\mathrm{Si}$ [8], полученными методом механохимического синтеза с последующим добавлением по разработанной технологии углеродных каркасных структур в виде нанотрубок, максимальная длина которых составляла около сотни микрон. Так как энергия деформации нанотрубок обратно пропорциональна квадрату радиуса, то использовались нанотрубки с диаметром в десятки микрон.

Сопротивление износу исследуемых покрытий оценивали трением модельных образцов по торцевой схеме контакта при распределенной нагрузке и в отсутствии смазки. Испытания осуществляли в режиме непрерывного скольжения при нагрузке 10,0 МПа. Толщина покрытий после финальной обработки составляла 0,20-0,30 мм при шероховатости $\mathrm{Ra}=0,63-0,32$. При этом по единым программам были испытаны покрытия того же состава, но не содержащие углеродные нанотрубки, а также традиционно используемые покрытия как из вольфрамсодержащих порошков типа ВК15, так и легированных на основе никеля.

Металлографическое изучение образцов, исследуемых покрытий, осуществляли с учетом специфики решаемых задач корректными методами комплексного физико-химического анализа.

\section{Результаты исследований и обсуждение результатов}

Основными факторами, определяющими развитие механо-химических процессов трения, от которых зависит степень и градиенты упругопластической деформации, температурные воздействия, структурно-фазовые превращения и, в конечном результате, ведущий вид изнашивания, являются скорости относительного перемещения, нагрузка, температура, окружающая среда. При этом существует прямая связь триботехнических параметров с процессами пластической деформации [9].

Результаты испытаний исследуемых покрытий представлены на рис. 1. зависимостями интенсивности изнашивания от значений скоростей скольжения при постоянной нагрузке, равной 10 МПа.

Как видно, наноразмерные покрытия системы $\mathrm{Nb}-\mathrm{V}-\mathrm{Si}$, имеющие в составе углеродные каркасные структуры нанотрубок, отличаются наименьшими значениями как длительности приработки и интенсивности изнашивания, так и коэффициента трения (рис. 1, кривые 1 и 11). При чем, следует отметить, что характер изменения коэффициентов трения согласуется с профилем кривой интенсивности изнашивания, а его стабильность во времени при монотонном увеличении скорости скольжения свидетельствует о высокой работоспособности материала покрытия, для которого ведущим является механо-химический износ.

Результаты микрорентгеноспектрального и рентгенофазного физико-химических исследований наноразмерных покрытий системы $\mathrm{Nb}-\mathrm{V}-\mathrm{Si}$, содержащих углеродные нанотрубки, позволили однозначно классифицировать их как тонкодифференцированную фазовую смесь со средним размером зерен 35-60 нм и практическиих равномерным распределением по сечению. Однако, также зафиксированы и фрагменты отпечатков, полученных в поглощенных электронах и рентгеновских лучах, которые соответствуют отдельным сгусткам с локальной неоднородностью, ультрадисперсная структура которых отличается от зернистой и близка к тонкопластинчатым образованиям. На наш взгляд, они обусловлены как наноразмерным фактором, так и тем, что при рентгеновских исследованиях таки основной вклад в интерференционную функцию вносят атомы металлов, так как атомный фактор рассеяния для них значительно больше, чем для металлоидов. Кроме того, их и содержание больше.

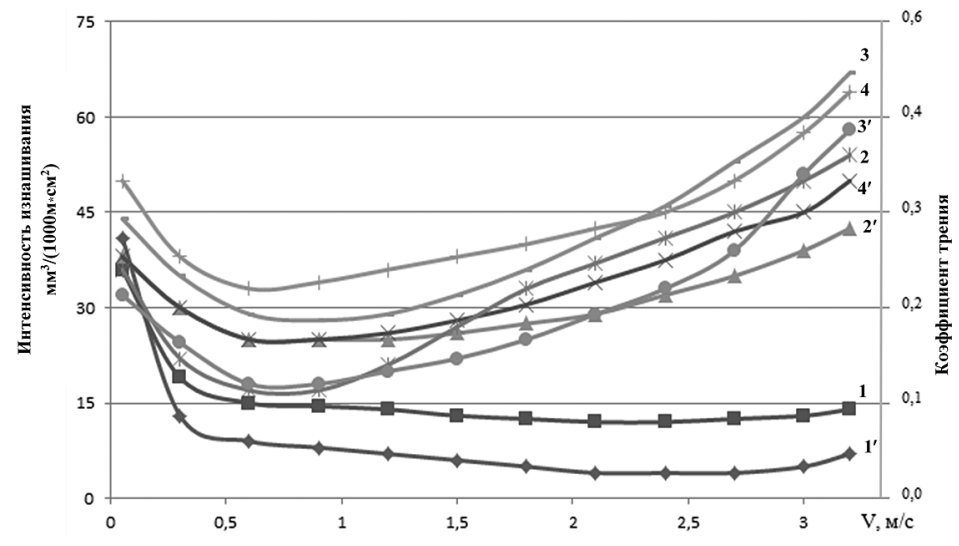

Рис. 1. Зависимость интенсивности изнашивания $(1,2,3,4)$ и коэффициентов трения $\left(1^{\prime}, 2^{\prime}, 3^{\prime}, 4^{\prime}\right)$ от скорости скольжения покрытий: 1, 1' - наноразмерная система $\mathrm{Nb}-\mathrm{V}-\mathrm{Si}$, содержащая углеродные нанотрубки; 2, 2' - типа ВК15 (WC-Co); 3, 3' - наноразмерный состав $\mathrm{Nb}-\mathrm{V}-\mathrm{Si} ; 4,4^{\prime}$ - на основе никеля (Ni-Cr-Al-B) 




$a$

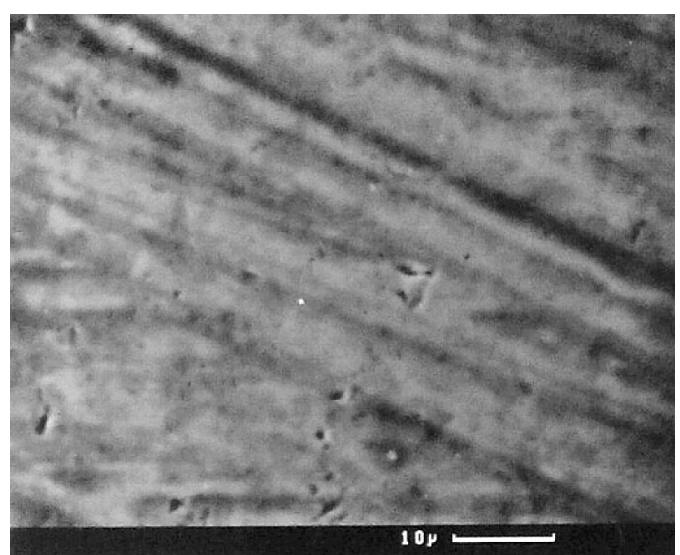

б

Рис. 2. Поверхности трения при $V=2,7$ м с и $P=10,0$ МПа: $\mathrm{a}$ - покрытия Nb-V-Si; б - покрытие $\mathrm{Nb}-\mathrm{V}-\mathrm{Si}$, содержащее углеродные трубки

Для оценки свойств наноразмерных композиционных покрытий и их поведения в условиях эксплуатации были установлены закономерности взаимодействия компонентов, входящих в их состав.

Установлено, что конгломерат ультрадисперсных составляющих покрытия представляют собой, прежде всего, химические соединения и механические смеси различного состава, величины и формы.

Идентифицировано наличие матричной фазы в виде твердых растворов $\mathrm{Nb}$ c $\mathrm{V}$ и $\mathrm{Si}$, также тройных твердых растворов с включениями химических соединений типа VSi. Следует отметить, что присутствие V и Si способствует повышению температуры рекристаллизации $\mathrm{Nb}$. Определены отличающиеся размерами, но с равным распределением по сечению, упрочняющие фазы сицилидов ниобия и ванадия $\left(\mathrm{Nb}_{5} \mathrm{Si}_{3}, \mathrm{NbSi}_{2},{ }_{5} \mathrm{Si}_{3}, \mathrm{VSi}_{2}\right.$ и пр.) и интерметаллиды ниобия и ванадия. Также установлено наличие распределенных по всему объему покрытия карбидов ниобия, ванадия, кремния ( $\mathrm{NbC}, \mathrm{VC}$, $\left.\mathrm{V}_{2} \mathrm{C}, \mathrm{SiC}\right)$ и сложных карбидных соединений типа $\mathrm{Me}_{\mathrm{m}}^{\prime} \mathrm{Me}_{\mathrm{m}}{ }_{\mathrm{m}} \mathrm{C}\left(\mathrm{Si}_{2} \mathrm{~V}_{2} \mathrm{C}, \mathrm{Si}_{2} \mathrm{Nb}_{2} \mathrm{C}\right)$.

Принципиальная особенность введения в состав наноразмерных покрытий углеродных каркасных образований в виде нанотрубок обусловлена эволюцией их атомов углерода в условиях активации. В процессе формирования гомогенной порошковой смеси в условиях механо-химическогосинтеза, атомы углерода концевых слоев нанотрубок активируются и в результате избирательного термодиффузионного взаимодействия образуют устойчивые химические соединения. Кроме того, в результате детонационно-газового напыления в условиях структурно-термической активации, атомы углерода инициируют связи с атомами металлов поверхностного слоя, способствуя формированию вторичных структур.

Процесс структурной активации определяется кинетикой зарождения и движения несовершенств кристаллического строения в зоне деформации, что в свою очередь связано с энергетическим состоянием атомов, зависящим от термической активации. За счет малых размеров (радиус атома углерода 0,77 aо) активированные атомы углерода, покидая каркасную структуру нанотрубок, легко диффундируют и их кооперативные скопления мигрируют к местам образования микротрещин, обладающих избыточной поверхностной энергией. Образующиеся при этом за счет сил химического и Ван дер Ваальсового притяжения атомарные мостики способствуют созданию межатомных связей и в результате блокировки развития трещин и их последующей аннигиляции. Таким образом, углеродные нанотрубки не только интенсивно участвуют в карбидизации поверхности и обеспечении создания антифрикционной пленки химически связанной с поверхностью наноразмерного слоя, но является источником активного углерода, способного к долговременной миграции и химическому взаимодействию при залечивании дефектов кристаллического строения, т.е. к уменьшению их концентрации, особенно в приповерхностных слоях, где сосредоточены как дислокационные скопления, так и микротрещины.

На рис. 2 а, б представлены характерные микрофотографии поверхностей трения. На рис. 2 а микрофотография рабочей поверхности образца покрытия $\mathrm{Nb}-\mathrm{V}-\mathrm{Si}$, не содержащего углеродных наноструктур, для которой типичным является развитие начальной фазы необратимых процессов деформации и повреждаемости.

Поверхность покрытия $\mathrm{Nb}-\mathrm{V}-\mathrm{Si}$, содержащего углеродные нанотрубки (рис. 2 б) характеризуется отсутствием следов макроскопических разрушений. Поверхность трения покрыта сплошной пленкой в основном темного цвета, не имеет дефектов, трещин, следов выкрашивания, что подтверждает ее высокую пластичность и адгезионную прочность. 
При рентгеновском спектральном микроанализе поверхности трения нанопокрытий с углеродными нанотрубками установлено наличие пленки $\alpha$-графита. Это, по мнению авторов, объясняется структурно-энергетическим фактором, а именно, энергия, частично запасенная поверхностью трения, сосредоточена, как известно, в тончайшем слое (порядка сотен нанометров) и ее плотность в единице активированного объема покрытия близка к критическому значению энергии, которую может поглотить материал до разрушения.

Высокая плотность запасенной энергии в условиях трибомеханических процессов контактного взаимодействия при аддитивном влиянии температурных флуктуаций и удельных давлений обуславливают в зоне трения одновременное проявление фактически всех возможных с точки зрения физико-химии аномальных превращений в твердой фазе. При этом, в результате термического разложения карбидов, освобождается структурно свободный х-графит, на основе которого формируется антифрикционная поверхностная пленка.

Полученные в результате испытаний данные позволяют констатировать, что защитный поверхностный тонкопленочный слой, содержащий графит, образуется уже в процессе приработки и его состав, как и равновесная шероховатость воспроизводятся во всем диапазоне нормальной работы и остаются практическими постоянными, что и обуславливает стабильность значений коэффициентов трения. При этом атомы металлов после частичной деструкции поверхностных карбидов образуют силицидные и, главным образом, оксидные фазы, которые, как показали субмикроструктурные исследования, заполняют поверхностные микронеровности, микротрещины и закрепляются в микровпадинах контактирующих поверхностей. Их противоизносные и антифрикционные действия сохраняются, по мнению авторов, длительно и соответствуют всему периоду нормальной работы сопрягаемых поверхностей и не связываются только с периодом приработки.
Достижение энергетического уровня, соответствующего изменению удельной работы разрушения, как показали расчеты, от 10 кДж/ мм $^{3}$ до

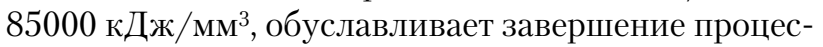
са приработки и определяет параметры трения, которые характеризуются минимизацией интенсивности изнашивания, корреляцией с коэффициентами трения, устойчивой шероховатостью и образованием оптимальных структур и свойств поверхностных слоев, обуславливающих протекание нормального изнашивания.

На рис. 3. представлены поверхности трения покрытия, содержащего углеродные нанотрубки, соответствующие режиму механохимического износа, в условиях которого показана кинетика процесса самокорректирования локальной микротрещины ( $V=2,5 \mathrm{~m} / \mathrm{c}, P=10,0 \mathrm{M \Pi а).}$

В условиях установившегося механо-химического износа, используя электронно-микроскопические исследования с применением метода темного поля удалось установить, что внутренняя приповерхностная зона представляет карбидно-оксидный конгломерат наноразмерных частиц, химически связанных с основным материалом. Внешний приповерхностный объект состоит из тонкого графитового слоя с некоторым количеством наноразмерных включений, однозначно идентифицировать которые не представилось возможным, однако, по нашему мнению, они даже в нанообъемах имеют сложный фазовый состав и состоят из смеси $\mathrm{Nb}_{2} \mathrm{O}_{5}(\mathrm{NbO}), \mathrm{V}_{2} \mathrm{O}_{5}, \mathrm{SiO}_{2}$.

В соответствии с современными взглядами, разрушение не является мгновенным актом, а представляет процесс, развивающийся во времени. С кинетической точки зрения, моменту образования трещины критического размера, способной распространяться самопроизвольно без подвода энергии извне (по гриффитсову механизму), предшествует постепенное накопление очагов разрушения в виде эндогенных микротрещин.

Инициирование явления внутриструктурной аннигиляции эндогенных микротрещин в припо-

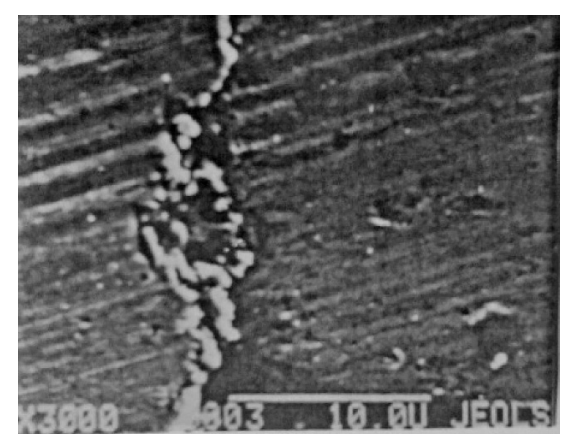

a

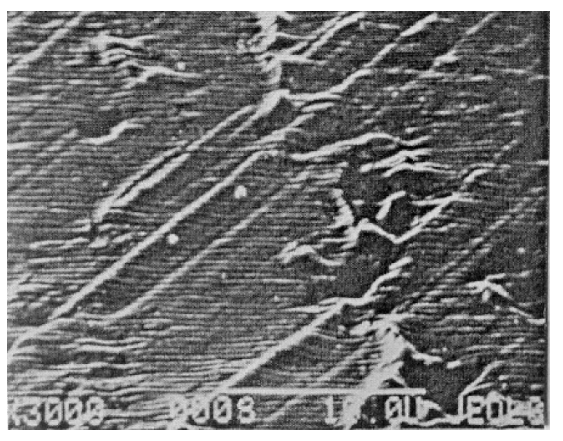

б

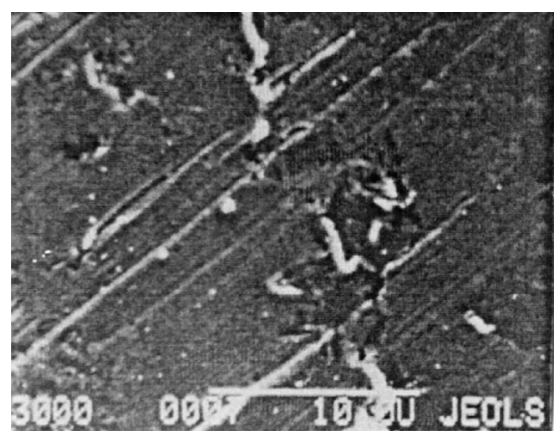

B

Рис. 3. Поверхности трения покрытия $\mathrm{Nb}-\mathrm{V}-\mathrm{Si}$, содержащего углеродные нанотрубки, иллюстрирующие кинетику процесса самокорректирования поперечной микротрещины ( $V=2,5$ м/с, $P=10,0$ МПа $)$ 
верхностных слоях покрытий осуществляется, вопервых, при наличии активированных атомов углерода, во-вторых, при самосогласовании двух взаимодополняющих процессов, с одной стороны, рабочей температуры, достигающей порядка 0,2-03 $T_{\text {пл }}$ с другой, действием полей сжимающих напряжений, охватывающих объем микротрещин, при котором активируются как диффузионная подвижность атомов углерода, так и трубчатая диффузия вакансий по ядрам дислокаций к поверхности.

Исследования поверхностных слоев, проводимые методами тонкого анализа, позволили выявить очаги микротрещин, возникающих при нагружении трением и установить, что их средние размеры, которые удалось идентифицировать, составляют от 0,8 до 2,0 мкм при концентрации порядка $10^{16}-10^{18} \mathrm{M}^{-3}$ (в объеме на два-три порядка меньше). Толщина поверхностного слоя с повышенной концентрацией микротрещин коррелирует с пористостью материала покрытий.

Таким образом, применение в составе наноразмерных покрытий углеродных каркасных структур является перспективным направлением инженерии поверхности, обеспечивающим существенное повышение износостойкости и долговечности изделий.

Представленная работа продолжает цикл систематических исследований по созданию перспективных наноматериалов для снижения коэффициентов трения и повышения износостойкости трибосопряжений.

\section{Выводы}

1. Установлена правомерность используемых методологий и алгоритмов проведения экспериментальных исследований повышения износостойкости детонационных наноразмерных композиционных покрытий за счёт внутриструктурного самокорректирования эндогенных микротрещин углеродными каркасными структурами в виде нанотрубок.

2. Отмечено, что активируемые атомы углерода не только образуют поверхностные карбиды, но за счёт размеров легко диффундируют и способны мигрировать к местам образования микротрещин, обладающих избыточной поверхностной энергией, и за счет химического и Ван дер Ваальсового притяжения способствуют блокировке их развития и последующей аннигиляции.

3. Установлено, что высокая плотность запасенной в поверхностном слое энергии в условиях трибомеханического взаимодействия при аддитивном влиянии термодинамических факторов и удельных давлений обусловливают в зоне фрикционного контакта всплеск практически всех возможных физико-химических аномальных превращений в твердой фазе. При этом в результате термического разложения карбидов, освобождается структурно свободный $\alpha$-графит.

4. Полученные результаты позволяют предположить, что антифрикционный поверхностный тонкоплёночный слой, содержащий графит, образуется в процессе приработки и его состав, как и равновесная шероховатость, воспроизводится и поддерживается, образуя целостную систему динамически устойчивых вторичных структур, во всём диапазоне нормального износа, отличительной особенностей которых является то, что они представляют собой активную среду, в каждом объеме которой запасается и выделяется энергия.

5. Установлено, что для проявления процессов внутриструктурного самокорректирования эндогенных микротрещин в приповерхностных слоях, кроме активированных атомов углерода, необходимо самосогласованное влияние как рабочей температуры, так и действие полей сжимающих напряжений, охватывающих объём микротрещин.

6. Результаты, полученные при испытаниях, подтверждают, что частичное залечивание накапливающихся в поверхностных слоях при трении эндогенных микротрещин за счет их внутриструктурного самокорректирования с помощью углеродных каркасных структур в виде нанотрубок более чем в два раза повышает долговечность покрытий.

\section{Литература}

[1] Петров А. И. Начальная стадия процесса залечивания пор и трещин в поликристаллических металлах в условиях всестороннего сжатия / А. И. Петров, М. В. Разуваева // Физика твердого тела. - 2005. T. 47. - № 5. - C. 880-885.

[2] Dienwiebel M., Verhoeven G. S., Pradeep N., Frenken J. W. M. Superlubricity of graphite // Phys. Rev. Lett. 2004. - 92. - P. 448-451.

[3] Кукуджанов К. В., Левитин А. Л. О воздействии высокоэнергетического импульсного электромагнитного поля на микротрещины в упругопластическом проводящем материале // Проблемы прочности и пластичности. - 2015. - Т. 77. - № 3. - С. 217-226.

[4] Song Hui [at al.]. Effect of high density electropulsing treatment on formability of TC4 titanium alloy sheet // Trans. Nonferrons Soc. China. - 2007. - v. 17. - P. 87-92.

[5] Степанов Г. В. Влияние обработки импульсным магнитным полем на сопротивление разрушению образца с трещиной / Г. В. Степанов, В. В. Харченко, А. А. Котляренко, А. И. Бабуцкий // Проблемы прочности. - 2013. - № 2. - С. 46-57.

[6] Gallo F., Satapathy S., and Ravi-Chandar K. Melting and crack growth in electrical conductors subjected to short-duration current pulses // Int. J. Fract. - 2011. 167. - P. 183-193.

[7] Котречко С. А. Предельная прочность. Кристаллы, металлы, конструкции: монография / С. А. Кот- 
речко, Ю. А. Мешков; НАН Украины. Ин-т металлофизики им. Г. В. Курдюмова. - К. : Наук. думка, 2008. -295 c.

[8] Патент 11394 Україна, МПК (2006): В22F 7/00, C22C 27/02 (2006.01), С23C 4/126 (2016.01), С23С 4/067 (2016.01). Високотемпературний зносостійкий наноматеріал / Бабак В. П., Щепетов В. В., Мірненко В. І., Яковлєва М. С.; заявник і патенто- власник Інститут технічної теплофізики НАН України. - № а201601802; заявл. 25.02.2016; опубл. 27.03.2017, Бюл. № 6/2017.

[9] Veprek S., Veprek-Heijman M. G. J., Karvankova P., Prochazka J. Different approaches to super hard coatings and nanocomposites // Thin Solid Films. 2005. - v. 476. - P. 1-29.

Babak V. P., Shchepetov V. V., Suprun T. T., Bilchuk Ye. Yu.

Institute of Engineering Thermophysics of National Academy of Sciences of Ukraine. Ukraine, Kiev

\section{WEAR RESISTANCE OF COATINGS DURING ANNIHILATION OF ENDOGENOUS EXTREME DEFECTS UNDER FRICTION}

Represented locking mechanism and subsequent annihilation endogenous microcracks due to their intrastructures self-correction.

Definitely, that for tribomechanical processes of frictional interaction, under the conditions of the additive effect of temperature fluctuations and specific loads, in the contact zone is a synchronously action of all probable anomalous reactions in the solid phase, as follows from the physico-chemical of the process. As a result, thermal destruction of carbides and the formation of $\alpha$-graphite with free structure.

Based on the results of the experiment, it can be concluded that the antifriction surface layer, which contains graphite, is formed in the breaking-in mode, and also, on the all range of normal wear, its composition and equilibrium roughness, are reproduced and maintained, forming an integral system of dynamically stable wear-resistant structures. [dx.doi.org/10.29010/080.2]

Keywords: detonation coating; wear resistance; surface layer; structural adaptability; alloying.

\section{References}

[1] Petrov A. I. The initial stage of the process of eliminating of pores and cracks in polycrystalline metals under conditions of all-round compression / A. I. Petrov, M. V. Razuvaeva // Physics of a solid. - 2005. - T. 47. - № 5. - P. 880-885.

[2] Dienwiebel M., Verhoeven G. S., Pradeep N., Frenken J. W. M. Superlubricity of graphite // Phys. Rev. Lett. - 2004. 92. - P. 448-451.

[3] Kukudzhanov K. V., Levitin A. L. On the effect of high-energy pulsed electromagnetic field on microcracks in elastoplastic conducting material // Problems of Strength and Plasticity. - 2015. - T. 77. - No. 3. - C. 217-226.

[4] Song Hui [at al.]. Effect of high density electropulsing treatment on formability of TC4 titanium alloy sheet // Trans. Nonferrons Soc. China. - 2007. - v. 17. - P. 87-92.

[5] Stepanov G. V. Effect of processing by a pulsed magnetic field on the resistance to fracture of a sample with a crack / G. V. Stepanov, V. V. Kharchenko, A. A. Kotlyarenko, A. I. Babutskiy // Problems of Strength. - 2013. - № 2. - P. 46-57.

[6] Gallo F., Satapathy S., and Ravi-Chandar K. Melting and crack growth in electrical conductors subjected to short-duration current pulses // Int. J. Fract. - 2011. - 167. - P. 183-193.

[7] Kotrechko S. A. Ultimate strength. Crystals, metals, constructions: monograph / S. A. Kotrechko, Yu. A. Meshkov; NAS of Ukraine. G. V. Kurdyumov Institute for Metal Physics of the National Academy of Sciences of Ukraine. - K.: Nauk. dumka, 2008. - 295 p.

[8] Patent 11394 Ukraine, IPC (2006): B22F 7/00, C22C 27/02 (2006.01), C23C 4/126 (2016.01), C23C 4/067 (2016.01). High-temperature wear-resistant nanomaterial / Babak V.P., Shchepetov V.V., Mirnenko V.I., Yakovleva M.S.; Applicant and patent-holder Institute of Technical Thermophysics of the National Academy of Sciences of Ukraine. № a201601802; stated. 25.02.2016; published. 27.03.2017, Bul. No. 6/2017.

[9] Veprek S., Veprek-Heijman M. G. J., Karvankova P., Prochazka J. Different approaches to super hard coatings and nanocomposites // Thin Solid Films. - 2005. - v. 476. - P. 1-29. 